\title{
Multiplex qPCR facilitates identification of betaherpesviruses in patients with acute liver failure of unknown etiology
}

Jéssica Vasques Raposo ${ }^{1}$, Arthur Daniel Rocha Alves ${ }^{2}$ Alexandre dos Santos da Silva², Damião Carlos dos Santos ${ }^{4}$, Juliana Gil Melgaço ${ }^{2}$, Otacílio C. Moreira ${ }^{3}$, Marcelo Alves Pinto ${ }^{2}$ and Vanessa Salete de Paula ${ }^{1,5^{*}}$

\begin{abstract}
Background: The etiology of acute liver failure (ALF) is often unknown and reported to be associated with herpesviruses in a number of cases. In this study, we examined for betaherpesviruses infections in patients with ALF of unknown etiology using a multiplex qPCR to Betaherpesviruses subfamily.

Methods: Liver explant and serum samples from 27 patients with ALF of unknown etiology were analyzed with the aid of multiplex qPCR to identify betaherpesviruses. All positive samples were sequenced to confirm herpes infection and liver enzyme levels evaluated.

Results: Betaherpesviruses infection was effectively detected using multiplex qPCR. Six (22\%) HHV-6, one (3\%) HCMV and two (7\%) dual infections (one with HHV-7/HHV-6, and the other with HHV-7/ HCMV). Interestingly, HHV-7 was only detected in the presence of other betaherpesviruses. Sequencing information confirmed betaherpesviruses infection. High hepatic enzyme levels and INR values> 1.5 were determined in all betaherpesvirus-positive patients.

Conclusions: Multiplex qPCR facilitated efficient quantification, indicating that differentiation between betaherpesviruses is possible with the sole use of real-time PCR. Liver explant and serum samples were positive for some betaherpesviruses, and coinfection of HHV-7 with HHV-6 and HCMV was additionally detected. Based on these results, we propose that ALF patients should be screened for the presence of betaherpesviruses.
\end{abstract}

Keywords: Betaherpesviruses, Acute liver failure, gPCR, Multiplex, Liver

\section{Background}

Acute liver failure (ALF) is a condition whereby healthy liver deteriorates rapidly, resulting in jaundice, encephalopathy and coagulopathy. According to the recently stablished diagnostic criteria, ALF may be defined when the interval between the appearance of jaundice and the development of coagulopathy and encephalopathy is up to 8 weeks [1]. The etiology of ALF cases is often unknown and some cases are not positive for hepatotropic viruses or other established potential factors [2]. Previous studies have reported the presence of viruses of the family Herpesviridae in cases of ALF, including the betaherpesviruses

\footnotetext{
* Correspondence: vdepaula@ioc.fiocruz.br

'Laboratory of Molecular Virology, Oswaldo Cruz Institute / Fiocruz, Rio de Janeiro, Brazil

${ }^{5}$ Oswaldo Cruz Foundation, IOC - Av. Brasil 4365-Manguinhos, Pav. Helio e Peggy Pereira B10, Rio de Janeiro 21040-360, Brazil

Full list of author information is available at the end of the article
}

human cytomegalovirus (HCMV), human herpesvirus 6 (HHV-6), and human herpesvirus 7 (HHV-7) [3, 4].

HCMV triggers an infection similar to mononucleosis syndrome while $\mathrm{HHV}-6 \mathrm{~A} / \mathrm{B}$ and $\mathrm{HHV}-7$ cause roseola infantum, febrile seizures and other febrile syndromes in children [4, 5]. After infection, betaherpesviruses remain latent until conditions in the immunocompromised host favor reactivation. HHV-6A/B and HHV-7 display genetic and biological homology and commonly manifest as sudden rash [6]. Primary HCMV and/or HHV-6A/B infections can cause mild and self-limiting hepatitis in immunocompetent patients. However, in immunocompromised cases, in particular, organ transplant recipients, HCMV infection is associated with increased morbidity [7]. Primary infection with HHV-6 is a frequent cause of ALF, necessitating antiviral therapy during early post-transplantation procedures. A number of studies have disclosed the presence of HHV-6

(c) The Author(s). 2019 Open Access This article is distributed under the terms of the Creative Commons Attribution 4.0 International License (http://creativecommons.org/licenses/by/4.0/), which permits unrestricted use, distribution, and 
in liver samples from pretransplant cases $[8,9]$. Complications resulting from $\mathrm{HHV}-7$ infection have also been identified as a risk in organ transplantation [10]. On the other hand, although have been rarely described, there are increasing evidences of association between some betaherpesviruses and ALF in immunocompetent patients [11-13].

Poor prognosis of hepatitis evolving from herpesvirus infection is associated with late diagnosis and delayed specific antiviral therapy, highlighting the urgent need for early detection. Currently, while several protocols exist for identification of the herpesvirus genome [14],multiple PCR assays are required for the process. In recent years, real-time PCR has been increasingly applied to simplify the overall procedure and reduce performance time in detecting and quantifying virus in clinical samples $[15,16]$. Multiplex qPCR has been suggested as an efficient alternative for simultaneous detection of HCMV, HHV-6 and HHV-7 within the same reaction [9, 17]. In the current study, the incidence of betaherpesvirus infection in patients with ALF of unknown etiology was investigated using the multiplex qPCR approach.

\section{Methods}

\section{Patients and samples}

The study group consisted of 27 patients with clinical signs of ALF (24 females and 3 males), who were attended at the hepatic transplantation service from Federal Hospital of Rio de Janeiro, Brazil. The protocol was approved by the Ethics Committee of the Oswaldo Cruz Institute (Protocol no. 440.614) and the written informed consent was signed by the patients or the responsible person. Inclusion criteria demanded the development of coagulopathy [i.e. prothrombin time activity (PTA) $>15 \mathrm{~s}$ or international normalized ratio (INR) > 1.5] and hepatic encephalopathy within 8 weeks of jaundice onset in the absence of preexisting liver disease. The clinical and haematological data of these patients, such as PTA, INR values and total bilirubin (TB) were obtained from medical records during the intensive care period. Exclusion criteria were any histological feature of chronic disease such as fibrosis.

Peripheral blood and liver explant samples were collected during the liver transplantation procedures. Peripheral blood were collected just before the hepatectomy procedure in trisodic citrate dextrose solution A/ACD-A (Greiner Bio-one, Kremsmünster, Austria). Fragments of liver explant were collected just after hepatectomy inside surgery center and immediately snap frozen in liquid nitrogen. As some patients died before liver transplantation, was not possible obtain liver explant samples of all patients. Thus, peripheral blood for testing were obtained from all patients and liver explant acquired from 14 patients. Samples had been previously determined as negative for hepatitis A, B, C, E and of unknown etiology.
Samples were examined via real-time multiplex PCR and confirmed using singleplex, qualitative PCR and nucleotide sequencing.

\section{Extraction of DNA}

Viral DNA was extracted using the QIAamp DNA Blood Mini Kit for serum samples and QIAamp DNA Tissue Mini Kit for liver samples (Qiagen, Germany), according to the manufacturer's protocols. DNA samples were stored at $-70{ }^{\circ} \mathrm{C}$ until processing.

\section{Multiplex qPCR for betaherpesviruses}

Betaherpesviruses were detected and quantified according to the method of Sassenscheidt and colleagues [18]. Oligonucleotide probes for detection of betaherpesviruses target highly conserved regions in the viral genome of published strains. For amplification of HCMV, we used UL54 and the U56 regions were used for HHV-6 A/B. This assay does not allow differentiation between consensus HHV-6 types A and B in clinical samples [18]. For detection of $\mathrm{HHV}-7$, the U37 region were used as described earlier [19]. Primers and oligonucleotide TaqMan probes are presented in Table 1. Multiplex qPCR was performed in a reaction mixture comprising $1 \mu \mathrm{L} 25 x$ PCR Enzyme (Mix Life Technologies, California, USA), $2.5 \mu \mathrm{L}$ of each oligonucleotide $(3 \mu \mathrm{M}), 2 \mu \mathrm{L}$ probe $(0.4 \mu \mathrm{M}), 12.5 \mu \mathrm{L}$ of $1 \mathrm{x}$ PCR Buffer (Life Technologies, California, USA) and $5 \mu \mathrm{L}$ DNA. Absolute quantification of DNA virus was performed with the aid of a synthetic standard curve designed for this study, ranging from 5 to $5 \times 10^{8}$ genome copies/ uL (Table 1).

\section{Singleplex qPCR for betaherpesviruses}

We employed the protocol described by Sassenscheidt et al. [18] using the same primers, oligonucleotide probes and amplification regions. For each reaction, a mixture comprising $1 \mu \mathrm{L}$ 25x PCR Enzyme (Mix Life Technologies, California, USA), $2.5 \mu \mathrm{L}$ each oligonucleotide $(1 \mu \mathrm{M})$, $2.0 \mu \mathrm{L}$ probe $(0.4 \mu \mathrm{M})$ and $12.5 \mu \mathrm{L}$ of $1 \mathrm{x}$ PCR Buffer (Life Technologies, California, USA) was used according to the manufacturer's instructions. Absolute quantification was performed based on the synthetic standard curve designed for this study.

\section{Specificity analysis}

Different targets of the Herpesviridae family were used for analysis of specificity. Serum samples positive for herpes simplex virus 1 and 2 (HSV-1 and HSV-2) and Epstein-Barr virus (EBV) were examined via previously standardized multiplex standard qPCR using betaherpesvirus targets as the negative control. 
Table 1 Sequences of primers, probes and standard curves

\begin{tabular}{|c|c|c|c|}
\hline & HCMV Sequence (5'-3') & HHV-6Sequence $\left(5^{\prime}-3^{\prime}\right)$ & HHV-7Sequence (5'-3') \\
\hline & FAM- & VIC- & NED - \\
\hline Probes & $\begin{array}{l}\text { CCGTATTGGTGCGCGATCTG } \\
\text { TTCAA- NFQ-MGB }\end{array}$ & $\begin{array}{l}\text { TTAGATGGTGGTGAGCT } \\
\text { GGGATCGGT- NFQ-MGB }\end{array}$ & $\begin{array}{l}\text { CTCGCAGATTGCTTGTTG } \\
\text { GCCATG- NFQ-MGB }\end{array}$ \\
\hline $\begin{array}{l}\text { Primers } \\
\text { (Sense) }\end{array}$ & GGCCGTTACTGTCTGCAGGA & $\begin{array}{l}\text { AAAGACCTAAATTGCCG } \\
\text { CTACCT }\end{array}$ & $\begin{array}{l}\text { CGGAAGTCACTGGAGTA } \\
\text { ATGACAA }\end{array}$ \\
\hline $\begin{array}{l}\text { Primers } \\
\text { (Anti-sense) }\end{array}$ & GGCCTCGTAGTGAAAATTAATGGT & $\begin{array}{l}\text { GCAAGCTCATGAACAT } \\
\text { CGTCA }\end{array}$ & CCAATCCTTCCGAAACCGAT \\
\hline $\begin{array}{l}\text { Standard } \\
\text { Curve }\end{array}$ & $\begin{array}{l}\text { TTCGTGGCCTCGTAGTGAAAATTAA } \\
\text { TGGTCGTATTTGAACAGATCGCGCA } \\
\text { CCAATACGGATGCGTTCCTGCAGA } \\
\text { CAGTAACGGCCCTGATA }\end{array}$ & $\begin{array}{l}\text { TTCGTGCAAGCTCATGAA } \\
\text { CATCGTCACGTATACCGA } \\
\text { TCCCAGCTCACCACCATC } \\
\text { TAAATGCGTAGGTAGCG } \\
\text { GCAATTTAGGTCTITCTGATA }\end{array}$ & $\begin{array}{l}\text { TTCGTCCAATCCTTCCGAA } \\
\text { ACCGATCGTATCATGGCCA } \\
\text { ACAAGCAATCTGCGAGATG } \\
\text { CGTITGTCATTACTCCAGTGA } \\
\text { CTTCCGCTGATA }\end{array}$ \\
\hline
\end{tabular}

\section{Reference control}

The TaqMan RNase P Control Reagent kit (Applied Biosystems Foster City, USA, Catalog number 4316844) was used as an internal reference control for analysis of human clinical samples to ensure the quality of DNA and exclude the possibility of false-negative results due to the presence of PCR inhibitors or low DNA integrity. TaqMan RNase P probe was 5 '-labeled with VIC fluorophore and 3'-labeled with NFQ-MGB. The reference control was used in qPCR singleplex assays and quality of samples monitored based on $\mathrm{Ct}$ values. The reaction mixture for RNase $\mathrm{P}$ control comprised $6 \mu \mathrm{L}$ DNase/RNase-free water, $1 \mu \mathrm{L}$ of $25 \mathrm{X}$ qPCR enzyme mix, $12.5 \mu \mathrm{L}$ of $2 \mathrm{X}$ qPCR buffer (including the reference dye ROX) and $1 \mu \mathrm{L}$ RNase P mix (containing oligonucleotides for this region and specific buffers; Applied Biosystems, California, USA) in 96-well plates. In addition, $5 \mu \mathrm{L}$ extracted DNA was subsequently added to the mix on the plate under similar conditions to those used in qPCR for betaherpesvirus detection.

\section{Qualitative Pan herpesvirus-PCR}

Samples showing positivity in qPCR were additionally examined via qualitative Pan-PCR only to confirm diagnosis. For simultaneous detection of betaherpesviruses, we employed the Pan herpesvirus technique based on amplification via nested PCR (Pan-PCR) of the Dpol gene, a highly conserved region in the herpesvirus genome, and species identification via sequencing of the viral genome. The protocol for herpesvirus detection and specific oligonucleotides were designed based on the report by Ehlers et al. [2].

\section{Sequencing}

Reactions were conducted in the DNA sequencing platform of the Technological Development Program in Health Supplies /PDTIS (Oswaldo Cruz Foundation, Rio de Janeiro, Brazil). Nucleotide sequences obtained were analyzed in the BioEdit 7.2.5 program and compared to other sequences deposited in GenBank with the BLAST tool (Basic Local
Alignment Search Tool) to identify the betaherpesvirus species detected using nested PCR.

\section{Biochemical analysis of samples}

Biochemical analyses were performed via spectrophotometric determination of pyruvic transaminase (ALT), oxaloacetic transaminase (AST) and alkaline phosphatase. Spectrophotometry procedures were performed using commercial kits (Abbott, Illinois, United States of America). For analysis of biochemical markers, samples were divided into three groups: betaherpesvirus-positive ALF samples ( $ß$-Herpesvirus positive), betaherpesvirus-negative ALF samples (ß-Herpesvirus negative) and healthy controls. Diagnosis of ALF was performed based on grade of encephalopathy along with prothrombin time (PT) and international normalized ratio (INR).

\section{Results}

\section{Detection and quantification of betaherpesviruses}

The mean age of patients was $25 \pm 18$ years, $75 \%$ of whom were female (Table 2). Nine (33\%) patients with ALF from previously unrecognized viral pathogens were positive for betaherpesviruses, specifically, six (22\%) HHV-6, one (3\%) HCMV and two (7\%) dual infections (one with HHV-7/ HHV-6, and the other with HHV-7/ HCMV). Interestingly, HHV-7 infection was detected only in the presence of other betaherpesviruses (Table 2). All samples showing

Table 2 Cycle threshold of qPCR specificity analysis for detection and quantification of betaherpesviruses

\begin{tabular}{ll}
\hline Target & Cycle Threshold (Ct) \\
\hline HCMV & 35.65 \\
HHV-6 & 31.12 \\
HHV-7 & 31.46 \\
HSV-1 & $U^{2} D^{a}$ \\
HSV-2 & $U^{a} D^{a}$ \\
EBV & $U^{a} D^{a}$ \\
Negative Control & $U^{a} D^{a}$
\end{tabular}

${ }^{a}$ Undetected 
Table 3 Descriptions and clinical outcomes of ß-herpesvirus populations positive for ALF of unknown etiology

\begin{tabular}{lllll}
\hline Patient & Sample & Gender & Clinical Outcome & B-Herpesviruses Positive \\
\hline FHF-3 & Liver & F & Death & HHV-6 \\
FHF -4 & Serum & F & Discharge & HHV-6 \\
FHF - 5 & Liver & M & Death & HHV-6/HHV-7 \\
FHF - 6 & Serum & F & Discharge & HCMV \\
FHF - 13 & Liver & F & Death & HHV-6 \\
FHF - 14 & Serum & M & Discharge & HCMV \\
FHF - 17 & Liver & F & Death & HCMV/HHV-6/HHV-7 \\
FHF - 26 & Liver & M & Death & HHV-6 \\
FHF - 27 & Liver & F & Discharge & HHV-6 \\
\hline
\end{tabular}

positivity in singleplex were also positive in the multiplex assay (Fig. 1).

\section{Specificity analysis}

In this experiment, betaherpesviruses were detected but no other herpesviruses tested, clearly indicating specificity for betaherpesvirus targets (Table 3)

\section{Reference control}

The internal reference control, RNase P, was used with negative samples for betaherpesviruses and samples from healthy patients. The $\mathrm{Ct}$ values and RNase P gene quantification remained constant, eliminating the possibility of false negative results (Table 4).

\section{Detection via Pan herpesvirus PCR and sequencing}

Nine positive samples were examined via Pan herpesvirus nested PCR and genome sequencing. In nested PCR using oligonucleotides to amplify the herpesvirus Dpol region, all samples previously positive with singleplex and multiplex qPCR were also positive for Pan herpesviruses. Sequencing was performed from Pan herpesvirus-positive samples
Table 4 Evaluation of human RNase $P$ gene as an internal reference control in TaqMan qPCR for betaherpesviruses

\begin{tabular}{llll}
\hline CtRNase P (ALF Samples) & \pm SD & CtRNase P (Controls) & \pm SD \\
\hline 29.93 & 0.07 & 27.55 & 0.01 \\
25.81 & 0.11 & 28.47 & 0.2 \\
27.06 & 0 & 28.46 & 0.12 \\
22.84 & 0.33 & 29.03 & 0.32 \\
\hline
\end{tabular}

SD Standard Deviation

using the Dpol region and all samples were successfully amplified.

\section{Biochemical analysis of samples}

Enzyme evaluation was performed on control samples and betaherpesvirus-positive and -negative ALF samples. In betaherpesvirus-positive ALF samples, alanine transaminase (ALT) and aspartate transaminase (AST) enzyme values were $>1000 \mathrm{U} / \mathrm{L}$. Additionally, hepatic alkaline phosphatase (ALP) presented elevated levels reaching $200 \mathrm{mg} / \mathrm{dL}$. The average of INR value was 5.25. In comparison, the above values were lower in betaherpesvirus-negative and control samples (Fig. 2).

\section{Discussion}

Poor prognosis of hepatitis evolving from herpesvirus infection is associated with late diagnosis and consequently, delayed initiation of antiviral therapy. One major reason for delayed diagnosis is the lack of specific symptoms. Typical mucocutaneous lesions are absent in half of the patients developing hepatitis [3, 17], highlighting the need for early diagnosis for optimizing therapy. In this study, 23.6\% samples from ALF patients displayed positivity for at least one of the betaherpesviruses. Our collective results support the utility of qPCR in detecting and quantifying HCMV, HHV-6 and HHV-7 in ALF samples of unknown etiology.

Recent years have seen an increased use of real-time PCR assays to simplify and reduce performance time and
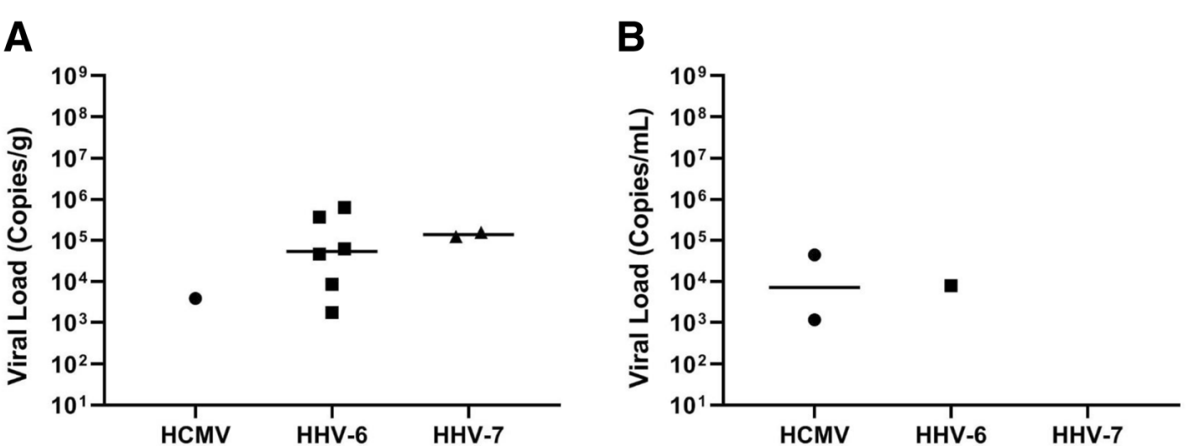

Fig. 1 Comparison of viral loads (copies/g) in liver (A) and serum (B) from patients with ALF of unknown etiology positive for betaherpesviruses, specifically, human cytomegalovirus (HCMV), human herpesvirus 6 (HHV-6) and human herpesvirus 7 (HHV-7) 


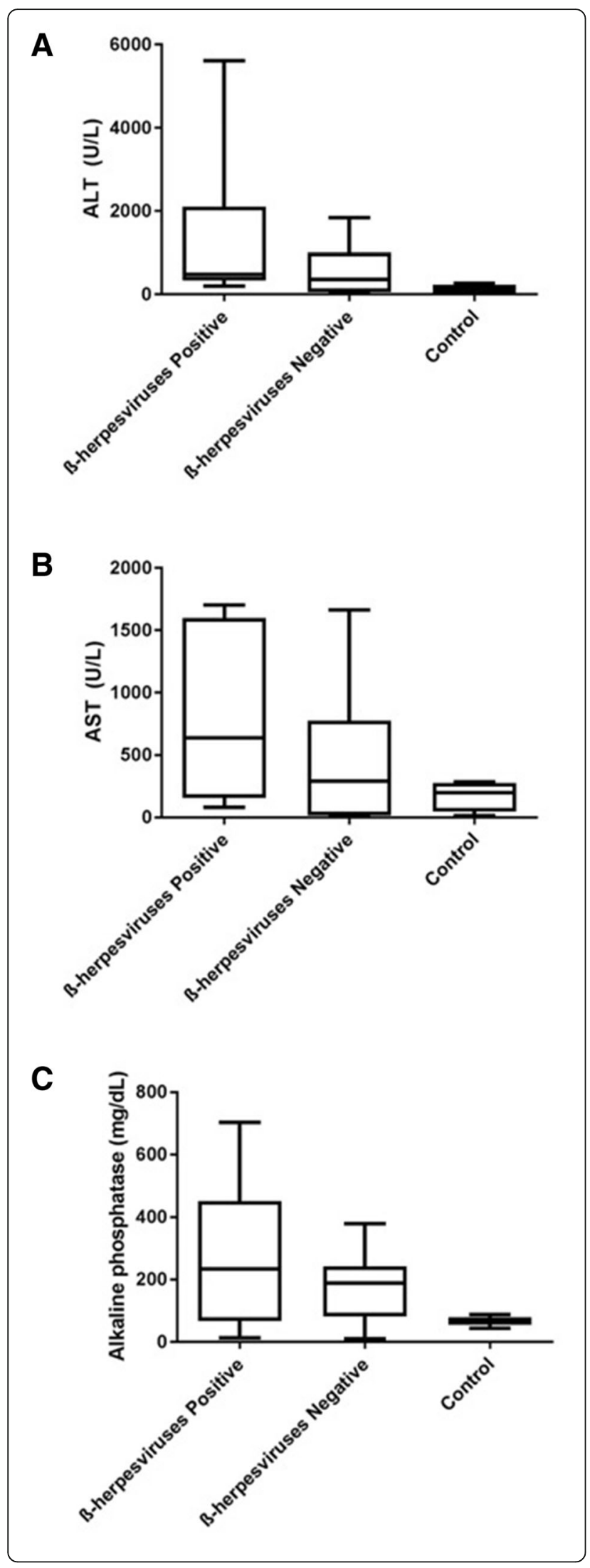

Fig. 2 Comparison of alanine transaminase (ALT), aspartate transaminase (AST) and alkaline phosphatase (ALP) levels among healthy control, betaherpesvirus-positive and -negative ALF patient samples

quantify virus in a single reaction [20]. In our experiments, RNase $\mathrm{P}$ as an internal reference control demonstrated the absence of false-negative results related to detection and quantification of betaherpesviruses in ALF samples with no defined etiology, supporting the accuracy of the results. In addition, multiplex qPCR was specific for betaherpesviruses, since we observed no amplification of other viruses of the Herpesviridae family examined, including HSV-1, HSV-2 and EBV. This result confirmed the specificity of the regions used for betaherpesvirus amplification as well as exclusion of false-positive results potentially caused by the interference of substances or organisms with similar sequences [14]. In the multiplex assays used in this study three fluorescence dye combinations were used to label the probes (FAM, VIC and NED). It allowed that the detection of three types of betaherpesvirus (CMV, HHV-6 and HHV-7). Furthermore, all samples identified as positive via $\mathrm{qPCR}$ were confirmed using Pan herpesvirus PCR and sequencing analyses. However, the multiplex is sufficient for screening ALF patients. Although hepatitis viruses are the most common cause of ALF, herpesviruses have also been associated with incidence of hepatitis [16, 21, 22].

In this study, three samples were detected as positive for HCMV. This virus has been reported in cases of liver transplantation in addition to being associated with induction of hepatitis $[23,24]$. The association of HCMV replication with ALF suggests a condition that increases the occurrence of HCMV infection after transplantation [24], leading to a requirement for prophylactic antiviral treatment to prevent HCMV infection in transplant recipients [25]. To date, studies have revealed that HCMV is not the main cause of ALF but rather the most common hepatic manifestation in immunocompromised patients [26].

Higher presence of HHV-6 was observed in the ALF samples tested. Among the samples positive for betaherpesviruses, $66 \%$ were HHV-6-positive. The greater positivity for HHV-6 corroborates with previous results showing that HHV-6 is more prevalent and pathogenic in ALF cases $[9,13]$. In another study, ALF was associated with primary HHV-6 infection in one child [27]. Several other HHV-6associated cases have been reported, mainly in infants $[8$, 12]. Earlier cases of ALF have similarly been attributed to HHV-6, although the virus is not yet classified as a causative agent of liver disease [4]. In a previously study, was showed that 12 of 15 patients with disease from an unknown cause and four of 17 patients with ALF from known causes contained HHV- 6 antigens in the explanted liver [8], along with a Brazilian case of ALF with HHV-6B [9]. 
Notably, positivity for HHV-7 was only detected in the presence of other betaherpesviruses. Two cases of dual infection (HHV-7/HHV-6 and HHV-7/HCMV) were identified within our patient population. Co-infection between roseoloviruses (HHV-6 and HHV-7) has been described in a previous studies on post-transplant patient liver samples [10]. Although, in this study was not possible demonstrate that HHV-6 precursor infection can induce subsequent HHV-7 infection, this co-infection should be better investigated.

Some evidence suggest that the molecular mechanisms of viral latency and reactivation are shared among these viruses. HHV-6B is reactivated from latency after coinfection with HHV-7 [28], and HCMV disease is frequently associated with concurrent HHV-6 and HHV-7 reactivation in transplant patients $[29,30]$. Studies have suggested an association between $\mathrm{HHV}-6$ and $\mathrm{HHV}-7$ reactivation and increased risk of CMV disease among kidney and liver recipients [31-33], but it is unclear if HHV-6 and 7 infection truly potentiates $\mathrm{CMV}$ disease or if the presence of these viruses represent more immunosuppression and attendant risk of CMV [34].

Evaluation of alanine transaminase (ALT) and aspartate transaminase (AST) enzyme levels disclosed values $>1000 \mathrm{U} / \mathrm{L}$ in ALF samples positive for betaherpesviruses. Destruction or injury of liver cells releases these enzymes into the circulation [35] and injury-related levels can reach up to 100 times the upper limit reference values of ALT and AST in cases of ALF. Values higher than $1000 \mathrm{U} / \mathrm{L}$ are usually reported in cases of viral hepatitis or hepatitis induced by drugs [35, 36]. Another biochemical parameter of liver function determined was INR of 5.25. The elevation time of coagulation represents low prothrombin production by hepatocytes.

Alkaline phosphatase (ALP) is not a hepatocyte-specific marker. However, ALF patients presented elevated levels of ALP of up to $200 \mathrm{mg} / \mathrm{dL}$. As determined previously, ALP displays small elevations in normal levels in cases of infectious hepatitis [35]. However, biochemical results disclosed no significant differences in values in hepatitis cases due to the limited sampling populations analyzed.

In our study, 55.5\% positive patients died, consistent with earlier literature showing that ALF often progresses to multiorgan failure, resulting in death or transplantation in 57\% cases [37] A significant proportion (12\%) of ALF cases worldwide are of unknown origin, often termed indeterminate [37]. In total $\sim 2000$ cases per year of liver failure are diagnosed in the United States [38], averaging $\sim 1$ to 6 cases per million worldwide. In Brazil, 2\% liver transplants are attributable to hepatic failure [39]. In the absence of information on etiology of the disease, late therapy is initiated in many cases, leading to ineffective treatment and ultimately death.
The incidence of betaherpesviruses (HCMV, HHV-6 and $\mathrm{HHV}-7$ ) is common worldwide. HCMV has a prevalence of $70-80 \%$ in adults [7]. HHV-6 and HHV-7 are ubiquitous, with higher prevalence in adults of up to $90 \%$ [40]. The high prevalence of betaherpesviruses can favor opportunistic infections, as seen in ALF, potentially due to virus reactivation as a result of decreased host immune system function [41, 42]. Betaherpesviruses-associated diseases may be decrease by prophylactic treatments with antiviral drugs [43]. Therefore, considering the interval among the appearance of early specific symptoms and the development of ALF, establishing the presence of active infection by herpesvirus in ALF patients is important to quickly start therapy with antiviral for prevent extensive liver damage.

\section{Conclusion}

Although we have not showed a clear association with betaherpesvirus and ALF, this is considered a rare cause. However, several cases of hepatitis highlighting herpesviruses as the most probable cause of this disease have been described in the literature. In keeping with previous findings, data from our study found betaherpesviruses in ALF cases and co-infection of HHV-7 with HHV-6 and CMV. Therefore, diagnosis should be made with caution after excluding classic hepatotropic viruses as another potential cause of disease. Evaluation of betaherpesviruses should be included for differential diagnosis in cases of ALF in order to improve specificity of treatment and minimize patient death. Thus, the multiplex qPCR used in this study simultaneously detected betaherpesviruses and may be useful for rapid and differential diagnosis in cases of ALF with unknown ethiolog.

\footnotetext{
Abbreviations

ALF: Acute liver failure; ALP: Alkaline phosphatase; ALT: Alanine transaminase; AST: Aspartate transaminase; EBV: Epstein-barr-virus; HCMV: Human Citomegalovirus; HHV-6: Human Herpes Virus 6; HHV-7: Human Herpes Virus 7; HSV-1: Herpes Simplex virus 1; PCR: Polymerase chain reaction; qPCR: Polymerase chain reaction quantitative
}

\section{Acknowledgments}

We gratefully acknowledge the kind assistance of the staff at the hepatic transplantation service at the Federal Hospital of Rio de Janeiro, and the time and cooperation of all study participants.

\section{Authors' contributions}

VSP and MAP did the conception and design of the study, DCS and JGM collected the data and the samples, JVR and ARA tested the sample, ASS conducted the statistical analyses, JVR, OCM and VSP performed the data analysis and interpretation, JVR and VSP wrote the article, All authors did a critical revision of the article and final approved the final version to be published.

\section{Funding}

This study was financed by the Coordenação de Aperfeiçoamento de Pessoal de Nível Superior - Brasil (CAPES) - Finance Code 001, Fundação de Amparo à Pesquisa do Estado do Rio de Janeiro (FAPERJ) and Oswaldo Cruz Institute who approved the project and funded the research with scholarship and grants. 


\section{Availability of data and materials}

The datasets used and/or analysed during the current study are available from the corresponding author on reasonable request.

\section{Ethics approval and consent to participate}

Ethical permission for the collection and testing of samples was provided by the Oswaldo Cruz Institute Ethical Committee (440.614). The written informed consent was signed by the patients or by parents/quardians on behalf of minors.

\section{Consent for publication}

Not applicable.

\section{Competing interests}

The authors declare that they have no competing interests.

\section{Author details}

'Laboratory of Molecular Virology, Oswaldo Cruz Institute / Fiocruz, Rio de Janeiro, Brazil. ${ }^{2}$ Laboratory of Technological Development in Virology, Oswaldo Cruz Institute / Fiocruz, Rio de Janeiro, Brazil. ${ }^{3}$ Laboratory of Molecular Biology and Endemic Diseases, Oswaldo Cruz Institute / Fiocruz,

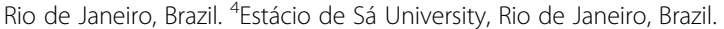
${ }^{5}$ Oswaldo Cruz Foundation, IOC - Av. Brasil 4365-Manguinhos, Pav. Helio e Peggy Pereira B10, Rio de Janeiro 21040-360, Brazil.

\section{Received: 9 April 2019 Accepted: 23 July 2019}

\section{Published online: 04 September 2019}

\section{References}

1. Mochida S, Takikawa Y, Nakayama N, Oketani M, Naiki T, Yamagishi Y, et al Diagnostic criteria of acute liver failure: A report by the Intractable HepatoBiliary Diseases Study Group of Japan. Hepatol Res. 2011;41(9):805-12.

2. Ehlers B, Borchers K, Grund C, Frolich K, Ludwig H, Buhk HJ. Detection of new DNA polymerase genes of known and potentially novel herpesviruses by PCR with degenerate and deoxyinosine-substituted primers. Virus Genes. 1999;18(3):211-20.

3. Abbo L, Alcaide ML, Pano JR, Robinson PG, Campo RE. Fulminant hepatitis from herpes simplex virus type 2 in an immunocompetent adult. Transpl Infect Dis. 2007;9(4):323-6.

4. Ishikawa K, Hasegawa K, Naritomi T, Kanai N, Ogawa M, Kato Y, et al. Prevalence of herpesviridae and hepatitis virus sequences in the livers of patients with fulminant hepatitis of unknown etiology in Japan. J Gastroenterol. 2002;37(7):523-30.

5. Lacoste V, Verschoor EJ, Nerrienet E, Gessain A. A novel homologue of human herpesvirus 6 in chimpanzees. J Gen Virol. 2005;86(Pt 8):2135-40.

6. Clark DA. Human herpesvirus 6 and human herpesvirus 7: emerging pathogens in transplant patients. Int J Hematol. 2002;76(Suppl 2):246-52.

7. Cisneros-Herreros JM, Herrero-Romero M. Hepatitis due to herpes group viruses. Enferm Infecc Microbiol Clin. 2006;24(6):392-7 quiz 8.

8. Harma M, Hockerstedt K, Krogerus L, Lautenschlager I. Pretransplant human herpesvirus 6 infection of patients with acute liver failure is a risk factor for posttransplant human herpesvirus 6 infection of the liver. Transplantation. 2006;81(3):367-72.

9. Paula VS, Silva AP, Michel D, Melgaco JG, Vieira YR, Santos DC, et al. Acute liver failure in an immunocompetent patient. J Clin Virol. 2014;60(1):1-3.

10. Fernandez-Ruiz M, Kumar D, Husain S, Lilly L, Renner E, Mazzulli T, et al. Utility of a monitoring strategy for human herpesviruses 6 and 7 viremia after liver transplantation: a randomized clinical trial. Transplantation. 2015; 99(1):106-13.

11. Yu YD, Park GC, Park PJ, Choi Yl, Hwang S, Song GW, et al. Cytomegalovirus infection-associated fulminant hepatitis in an immunocompetent adult requiring emergency living-donor liver transplantation: report of a case. Surg Today. 2013;43(4):424-8.

12. Charnot-Katsikas A, Baewer D, Cook L, David MZ. Fulminant hepatic failure attributed to infection with human herpesvirus 6 (HHV-6) in an immunocompetent woman: A case report and review of the literature. J Clin Virol. 2016;75:27-32.

13. Arribas Anta J, Zaera de la Fuente C, Graus Morales J, Lopez Duran S, Canete Ruiz A, Gea Rodriguez F, et al. Fulminant hepatitis caused by herpes virus 6 in immunocompetent adults. Gastroenterol Hepatol. 2016;39(8):533-4.
14. Burd EM. Validation of laboratory-developed molecular assays for infectious diseases. Clin Microbiol Rev. 2010;23(3):550-76.

15. Fellner MD, Durand K, Rodriguez M, Irazu L, Alonio V, Picconi MA. Duplex realtime PCR method for Epstein-Barr virus and human DNA quantification: its application for post-transplant lymphoproliferative disorders detection. Braz J Infect Dis. 2014;18(3):271-80.

16. Fernandes-Monteiro AG, Trindade GF, Yamamura AM, Moreira OC, de Paula VS, Duarte AC, et al. New approaches for the standardization and validation of a real-time qPCR assay using TaqMan probes for quantification of yellow fever virus on clinical samples with high quality parameters. Hum Vaccin Immunother. 2015;11(7):1865-71.

17. Riediger C, Sauer P, Matevossian E, Muller MW, Buchler P, Friess H. Herpes simplex virus sepsis and acute liver failure. Clin Transpl. 2009; 23(Suppl 21):37-41.

18. Sassenscheidt J, Rohayem J, Illmer T, Bandt D. Detection of betaherpesviruses in allogenic stem cell recipients by quantitative real-time PCR. J Virol Methods. 2006;138(1-2):40-8.

19. Hara S, Kimura H, Hoshino Y, Tanaka N, Nishikawa K, Ihira M, et al. Detection of herpesvirus DNA in the serum of immunocompetent children. Microbiol Immunol. 2002;46(3):177-80.

20. Nishiwaki M, Fujimuro M, Teishikata $Y$, Inoue $H$, Sasajima $H$, Nakaso $K$, et al. Epidemiology of Epstein-Barr virus, cytomegalovirus, and Kaposi's sarcomaassociated herpesvirus infections in peripheral blood leukocytes revealed by a multiplex PCR assay. J Med Virol. 2006;78(12):1635-42.

21. Al Midani A, Pinney J, Field N, Atkinson C, Haque T, Harber M. Fulminant hepatitis following primary herpes simplex virus infection. Saudi J Kidney Dis Transpl. 2011;22(1):107-11.

22. Gallegos-Orozco JF, Rakela-Brodner J. Hepatitis viruses: not always what it seems to be. Rev Med Chil. 2010;138(10):1302-11.

23. Herman D, Han H. Cytomegalovirus in liver transplant recipients. Curr Opin Organ Transplant. 2017;22(4):345-50.

24. Davalos F, Chaucer B, Zafar W, Salman S, Nfonoyim J. Dasatinib-induced CMV hepatitis in an immunocompetent patient: a rare complication of a common drug. Transl Oncol. 2016;9(3):248-50.

25. Mutimer DJ, Shaw J, O'Donnell K, Elias E. Enhanced (cytomegalovirus) viral replication after transplantation for fulminant hepatic failure. Liver Transpl Surg. 1997;3(5):506-12.

26. Qian JY, Bai XY, Feng YL, Zhu WJ, Yao F, Li JN, et al. Cholestasis, ascites and pancytopenia in an immunocompetent adult with severe cytomegalovirus hepatitis. World J Gastroenterol. 2015;21(43):12505-9.

27. Asano Y, Yoshikawa T, Suga S, Yazaki T, Kondo K, Yamanishi K. Fatal fulminant hepatitis in an infant with human herpesvirus-6 infection. Lancet. 1990;335:862-3

28. Katsafanas GC, Schirmer EC, Wyatt LS, Frenkel N. In vitro activation of human herpesviruses 6 and 7 from latency. Proc Natl Acad Sci U S A. 1996; 93(18):9788-92.

29. Lautenschlager I, Lappalainen M, Linnavuori K, Suni J, Hockerstedt K. CMV infection is usually associated with concurrent HHV-6 and HHV-7 antigenemia in liver transplant patients. J Clin Virol. 2002;25(Suppl 2):S57-61.

30. Mendez JC, Dockrell DH, Espy MJ, Smith TF, Wilson JA, Harmsen WS, et al. Human beta-herpesvirus interactions in solid organ transplant recipients. J Infect Dis. 2001;183(2):179-84.

31. Pan $H$, Feng DN, Song L, Sun LR. Acute myeloid leukemia following etoposide therapy for EBV-associated hemophagocytic lymphohistiocytosis: a case report and a brief review of the literature. BMC Pediatr. 2016:16:116.

32. Harma M, Hockerstedt K, Lyytikainen O, Lautenschlager I. HHV-6 and HHV-7 antigenemia related to CMV infection after liver transplantation. J Med Virol. 2006;78(6):800-5.

33. Kidd IM, Clark DA, Sabin CA, Andrew D, Hassan-Walker AF, Sweny P, et al. Prospective study of human betaherpesviruses after renal transplantation: association of human herpesvirus 7 and cytomegalovirus co-infection with cytomegalovirus disease and increased rejection. Transplantation. 2000; 69(11):2400-4.

34. Pellett Madan R, Hand J. Human herpesvirus 6, 7, and 8 in solid organ transplantation: Guidelines from the American Society of Transplantation Infectious Diseases Community of Practice. Clin Transplant. 2019:e13518.

35. MOTTA VT. Bioquímica Clínica: Princípios e Interpretações. 5th ed; 2008.

36. Parker ZM, Pasieka TJ, Parker GA, Leib DA. Immune- and NonimmuneCompartment-Specific Interferon Responses Are Critical Determinants of Herpes Simplex Virus-Induced Generalized Infections and Acute Liver Failure. J Virol. 2016;90(23):10789-99. 
37. Somasekar S, Lee D, Rule J, Naccache SN, Stone M, Busch MP, et al. Viral surveillance in serum samples from patients with acute liver failure by metagenomic next-generation sequencing. Clin Infect Dis. 2017:65(9):1477-85.

38. Lee WM, Squires RH Jr, Nyberg SL, Doo E, Hoofnagle JH. Acute liver failure: summary of a workshop. Hepatology. 2008;47(4):1401-15.

39. Squires RH Jr, Shneider BL, Bucuvalas J, Alonso E, Sokol RJ, Narkewicz MR, et al. Acute liver failure in children: the first 348 patients in the pediatric acute liver failure study group. J Pediatr. 2006;148(5):652-8.

40. Razonable RR. Human herpesviruses 6,7 and 8 in solid organ transplant recipients. Am J Transplant. 2013;13(Suppl 3):67-77 quiz -8.

41. Ogata M. Human herpesvirus-6-associated diseases in hematopoietic stem cell transplantation: an update. Rinsho Ketsueki. 2016;57(3):298-306.

42. Dandamudi R, Smith J, Dharnidharka VR. Renal transplantation and predisposition to opportunistic infections. Curr Opin Pediatr. 2019; 31(2):226-31.

43. De Bolle L, Naesens L, De Clercq E. Update on human herpesvirus 6 biology, clinical features, and therapy. Clin Microbiol Rev. 2005;18(1):217-45.

\section{Publisher's Note}

Springer Nature remains neutral with regard to jurisdictional claims in published maps and institutional affiliations.

Ready to submit your research? Choose BMC and benefit from:

- fast, convenient online submission

- thorough peer review by experienced researchers in your field

- rapid publication on acceptance

- support for research data, including large and complex data types

- gold Open Access which fosters wider collaboration and increased citations

- maximum visibility for your research: over $100 \mathrm{M}$ website views per year

At BMC, research is always in progress.

Learn more biomedcentral.com/submissions 